\title{
Research on Returned Logistics and Its Models for Wasted Electrician Product
}

\author{
Zhang Qian ${ }^{1}$, Shen Zhongming ${ }^{2}$ \\ School of Economics and Finance, HuaQiao University P. R. China \\ ${ }^{1}$ zhangyl@ hqu.edu.cn, ${ }^{2}$ zhongminghqu@ sina.com
}

\begin{abstract}
Operational models for waste recycle is established based on the theory of closed loop supply chains and an analysis cast on centralized and decentralized decision making in the process of waste recycle with game theory adopted. The present situation and existing problems are subsequently discussed before an accumulate data process of the data of 9 experimental provinces and 19 other provinces built on which an empirical study is performed on the effects that selling price and recycling price respectively have on sales volume and recycle volume. The results revealed that the implementation of "old-for-new" service has considerably promoted the sales of household appliances, not only bringing benefits to manufacturers, Retailers and consumers, but also reducing the harm to environment by boosting the recycle and reuse of waste.
\end{abstract}

Index Terms - closed loop supply chains, game theory, returned logistics, pricing model

\section{Introduction}

Since the closed-loop supply chain is not only able to achieve the protection of the environment and efficient use of resources, but also to achieve the sustainable development of enterprises, so a lot of literature has the qualitative and quantitative research on the closed-loop supply chain. Karl Interfaith, Ruud H.Teunter pointed out that the closed-loop supply chain a significant feature is the recovery of product recovery and remanufacturing. The recyclables from the consumer may also come from the supply chain of various joints, such as the existence of producing defective products, or damaged products, etc. in the distribution channel. Bloemhof-Ruwaard deems that the closed-loop supply chain in reverse logistics process consists of three activities: (1) waste products from the final consumer to return to the manufacturer's physical activities; (2) The manufacturer transform the waste products into the activities of the supplies; (3) re-use of waste products, product design activities. May be found in the first two activities is a waste product recycling activities, activities of the latter is to ensure that the waste products can take advantage of lower costs and efficiency. Specific logistics activities included in the above activities are: (1) recycling of waste materials; (2) test of waste materials; (3) reprocessing of waste materials; (4) landfill or incineration of waste materials; (5) re-distribution, waste product after this process can continue to circulate in the market, the product is about distribution to the needs of market. Krikke pointed out that the goal of implementing of the closed-loop supply chain is the cycle use of renewable waste and to reduce waste emissions relate with reduce the impact on the environment, to provide customers with services at a lower cost. Geyer and
Jackson also thought that economic goals and environmental goals is the supply chain of the closed-loop two goals. Roland Clift and Lucy Wright, using a large number of data in mobile phone industry, the conclusions to draw the value of the supply chain at every stage of proliferation is out of proportion to impact on the environment. The article summed up with the extension of the supply chain, the impact of each stage on the environment and the ratio of the value added is getting smaller and smaller, which shows that the extended supply chain and reverse logistics, thereby achieve the goods re-use and recycling, then this will be good promotional sense for build a resource-saving and environment-friendly society. At present, in many countries, producer responsibility extends to the production of the entire product life cycle, it can be through the entire product life cycle management to achieve environmental protection requirements.

\section{The Mode Analysis of Recycling Waste Electronic Products in Our Country}

Waste electrical and electronic product recycling regulations have passed on August 20, 2008 with the State Council executive meeting, effective January 1, 2011. Therefore, the purpose of investigate the implementation of the closed-loop supply chain management is for conserve resources, reduce waste of resources and improve the cycle of resource use efficiency, achieve resource - production consumption - renewable resources "closed loop cycle so as to achieve the protective effect on the environment. This article describes the reverse recovery process of waste electronic products use a specific use case of the closed-loop supply chain management, combination of the above analysis of the recycling of waste electronic products in Japan and China's current situation, summed up for our country's waste.

\section{A.Closed loop supply chain information platform construction}

To make the closed-loop supply chain each link can effective implementation and operation, building a based on closed loop supply chain is the key for members of the platform of information system. based on the Internet, each member of the information systems to link up, and using the data exchange interface ( EDI ), geographic information system ( GIS ), Global Positioning System ( GPS ), tuners data interface techniques of the system data fusion, to construct an open channels of information to achieve the information is accurate, in time, fully sharing. Information system model as shown in Figure 1. 


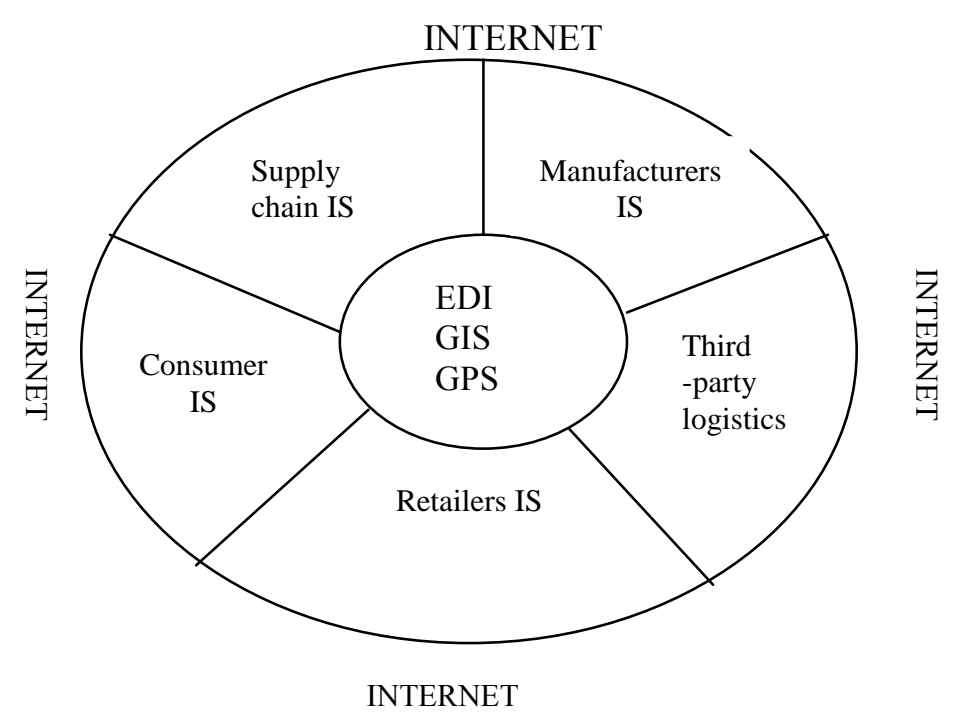

Fig.1 Information System model

\section{B. Government's role in Closed-loop Supply Chain Management}

Each member on the supply chain is the main part to implement supply chain management, so government which is in the leading level plays a guiding role towards the whole supply chain .The government can implement the Closed-loop Supply Chain Management as below: Develop and improve relevant laws and regulations in recycling of waste. On 28 February,2006,Electronic Information Products Pollution Control and Management Methods, was released to the public which is the first law about the abandoned electronic products in China and it came into effect on o1 March,2007.Its main purpose was to limit the use of poisoned materials(Lead, Mercury, Cadmium, Hexavalent Chromium, PBB, PBDE) in the electronic products. Decreasing the use of these materials in the production and designing part to reduce damages to environment pollution and human body.

Abandoned Household Appliances and Electronic Products Pollutions Control Technological Policies, was issued and practiced on 27 Aprial, 2006 and its aim was to realize the E-waste reduction, resource and harmless. Reduction means reducing the emissions of abandoned electronic products; resource means realizing the recycling for the abandoned electronic products resources; harmless means decreasing the environment pollution which abandoned electronic products bring in the recycling link. It follows the principles of "polluter responsible" and each member on the supply chain legally shares the responsibility in a process during abandoned electronic products are being recycled. So the government should play the leading role to promote environmental-protection knowledge to the public and train them the environmental-protection consciousness, for instance, dispatching booklets to citizens, marking environmental protecting signs in public places, posting environmental protecting knowledge in metro, bus and railway stations etc., also can introduce the environmental protecting into class, thus can realize the effect with the resources saving and environment protection.

\section{The Development of Discarded Electronic Products Market in China and the Design of Recovery Mode}

As the improvement of our resident income level, the consumer's demand of the electronic products is increasing .Meanwhile, the electronic products have the feature of firstly newest period. There is some useful resource in the abandoned electronic products, such as Copper, Aluminum, Iron and some kinds of rare metal, glass, plaste etc. which have highly recycle value. The cost of get resource from the rebirth is more less than directly smelt and process form the mineral, raw material. Enhance the recycle of the abandoned electronic products have very important reality meaning on the development of recycle economy and overcome the resource shortage's restrict to Chinese economy 's development. China as a big country of electronic products' production and consumption, regulate the abandoned electronic products' reclamation and treatment will benefit on prevent and reduce environment pollution, boost resource general use ,develop recycle economy, found conservationoriented society.

\section{The Development Status of Our Abandoned Electronic Products' Market}

At present, the trend of our abandoned electronic products: First, from consume terminal recycle or through factory, retailer use the service of "old for new service" to recycle and then enter second-hand market and sell to low end consumers. Second, unweave, deal with or collect rare metal resource. Third, the final consumers directly abandon it. And nowadays the environment pollution problem is focus on the first and second trend: due to there is some unweaving 
abandoned electronic products handwork workshop. They go for short-term profit, use open burning, acid soaking and other primitive methods to collect precious metal, and then discharge waste gas, liquid, and residue at their will. Those are very harmful to atmosphere, soil and water, also to people's health. Though the government pays much attention to the environment and health problem which is triggered by electronic used products, the cooperation among different departments is not very good, then produce the regulatory gap. Thus, it is essential to strength law-based control for treatment of used electronic products to maintain sustainable development.

The two issues reflected by now used electronic market are: the routine for recycle of the e-waste is not norm, the lowlevel for treatment cause environmental pollution and waste of resources; second, a new economic pattern exits in the back of the recycling for e-wastes. Once the issue is solved, the ewaste's pollution will be ok. So, building a norm recycle system is quite important. As a whole, the small venders are the essential part of recycling for e-wastes. In the process, they cannot satisfy environmental requirements. In spite of the government Promulgated Electronic products recycling waste management regulations, but only the efforts of the government and manufacturer is not enough, it need supports from all of us.

\section{Product Recycling System in China of Fuji Xerox}

The system of Fuji Xerox is conducted via the integration of resources circulation system. It is the first one for used electronic products and Se drum, reuse the new resources come from the e-wastes. The collected used products are divided into 70 parts, as iron, aluminum, glass, lens and so on. These parts will be reused or reproduced into raw material. These raw materials would passed on to partners to manufacture different kinds of products. During this process, no waste, no bury, no pollution.

In this process, Fuji Xerox use a set of logistics IMS to control and record the whole unweave, classification. The recycled products and parts will be weighed many times, make the original material's weight march the unweaves parts', to assure zero-waste. Fuji Xerox's integration of resources circulation system can reduce the usage of new resource to the lowest level, meanwhile can solve e-wastes' pollution issue completely, come true the goal for "zero-bury, zero-pollution, non-illegal waste". At present, Fuji Xerox do not benefit from this system, which is the reason why domestic firms pay a negative attitude to recycling system of e-waste. See the practice world widely, manufacture-recycle" duty of factory is very clear. To companies, the obstacle is cost and benefit problem for investing this system. Besides, domestic firms lack of the power for self-construction resource recycling; the reason is that it is difficult to reclaim used products. Consequently, we need to build a close-loop supply chain to encourage every part to join in. Only in this way, it can minimize the social cost.

\section{The Design of the Recovery Mode}

For the large electronics manufacturers, through their own sound channels and platforms to achieve the recycling of discarded electronic products. Most of the small manufacturers lack the resources and funding to implement the recycling of waste electronic products. Therefore, the government departments should be preferential policies on third-party recyclers. Through tax breaks and special subsidies to support the growth of third-party recyclers. In China, Japan, South Korea and other Asian countries, it is generally rich in lithium, titanium, gold, indium, silver, cobalt and palladium and other precious metal waste electrical and electronic products called "urban mines". recyclers and local government should cooperative use of "urban mines". Third-party related research shows that in 2010, the retirement of home appliances in Chinese society to reach 50 million units, more than 1.5 million tons. In addition, computer ownership in China nearly 20 million units, about 190 million mobile phones, there are about 5 million computers, tens of millions of mobile phones into disuse. Improper handling of this e-waste will be cause serious pollution to the atmosphere, water and soil the impact of e-waste on human health has become a prominent social problem. The city mine accumulation trend corresponds to the urgent needs of our mineral resources, the annual consumption of mineral resources in China has surpassed the U.S. as the world's resource consumption superpower. Large number of foreign raw ore to be imported annually to meet domestic market demand, China's "urban mines" of the recovery rate is significantly lower, such as cobalt and nickel resource recovery rate of only about $20 \%$ or even less than $10 \%$ in some provinces and municipalities.

\section{Electronic Product Analysis- Based on Home Appliance Product}

The electronics industry is a rapidly growing industry, product updates upgrade, scrap electronic products will be more and more, China's electronic product growth rate of $3 \%$ $-5 \%$ per year, this rate is three times the growth of municipal solid waste speed. Electronic products are convenience for human life, it also brings a lot of waste electronic products at the same time. On one hand, they contain harmful chemicals on the environment caused by pollution, on the one hand, which contains a lot of re-use a variety of precious metals, etc., with high economic value and use value. This section will combine the electronic products in the appliance market, to provide a basis for exploration and research. This section of the country's leads to its recovery. As already mentioned the "New for Old " policy began in June 2009, involving mainly five categories of televisions, refrigerators, washing machines, air conditioners, computers in household electrical appliances, first in Shanghai, Beijing, Tianjin, Zhejiang, Jiangsu, Guangdong, Shandong, Changsha, Fuzhou, nine pilot provinces and cities, and gradually extended to 19 provinces and cities to June 2010. Trade-in policy is aim to the urban and rural residents, the Government is also increase investment, and financial subsidies to consumer's . This policy central 
financial subsidies accounted for $80 \%$ subsidy which accounted for $20 \%$ of the local financial. Consumers in the replacement of old home appliance in addition obtains the recycling price, what is more, still can be obtained the purchase price of $10 \%$ of the price subsidies in buy new appliances, consumers have benefited, which greatly stimulated the consumers' purchasing desire that the policy is fairly obvious leading role. In short, the "New for Old " policy may implement to greatly enhance the consumption of appliances, which not only bring profits to the manufacturers and retailers, but also consumers gain the benefits. However, it also brought a large number of waste household electrical appliances, which requires us to enjoy concessions, think of how scientific reprocessing and reuse of the waste products at the same time, to reduce its impact on the environment.

\section{Acknowledgements}

This work was financially supported by the National natural science Foundation (71040009), and Ministry of Education, New Century Excellent Talents funded projects (No.NCET-10-0118).

\section{References}

[1] Shih L H. Reverse logistics system planning for recycling electrical appliances and computers in Taiwan. Resources, Conservation and Recycling, 2001, 32(1):55-72.

[2] Fleischmann M. Quantitative models for reverse logistics. The Netherlands: Erasmus University Rotterdam, 2001.
[3] Karl Inderfurth. Ruud H. Teunter. Production planning and control of closed-loop supply chains. London: Econometric Instiute Report EI. 2001:39-40.

[4] Bloemho-Ruwaard. J.B., P. van Beek, et al. Interactions between Operations Reserch and Environmental Management. European Journal of Operational Reserarch, 1995, 8(85): 229-243.

[5] Krikke, H., Pappis, C. P., Tsoulfas, G.T., Bloemhof-Ruwaard, J., Design Principles for Closed loop Supply chains: Optimizing Economic Logistics and Environmental Peformance, Working Paper. 2001, INSEAD. Retrieved April 28, 2004 from http://www.insead.edu.

[6] Geyer, R., Jackson, T., Supply loops and their constraints: The industrial ecology of recycling and reuse. California Management Review, 2004, 46(2):55-73.

[7] Roland Clift, Lucy Wright. Relationships between Environmental Impacts and Added Value a long the Supply Chain. Technological forecasting and social change, 2000, 6(7):281-195.

[8] Wang, Jiang, and Shen: Channel performance under Consignment Contract with Revenue Sharing Management Science 2004, 50(1), 3447.

[9] Wei-Ying Zhang, Game Theory and Information Economics. Shanghai: Shanghai People's Publishing House, 1996.

[10] Liu Mei, Extended Producer Responsibility System of electronic waste management. China Population, Resources and Environment, 2006(2): $120-123$

[11] Han Zhang and Tian Zhou, Japanese home appliance industry recycling manufacturing mechanism and the enlightenment of china's policy. Appliance Technology, 2004(10): 38-42

[12] Zhou, Extended Priducer Responbility and Corporate Strategies. Resources and utilization technology of electronic waste of Policy Symposium, 2004:9-12

[13] Feng, Development of circular economy and the research of countermeasures in China. Shijiazhuang: Hebei Normal colleges,2006

[14] Zhang, Analysis of the mode of competition and business strategy of the home appliance chain enterprises. Techno-economic market, 2007(4): $110-111$ 